\title{
Analytically Modeling, Design and Analysis a Nonlinear Controller for a Statcom Operations
}

\author{
J. K. Moharana \\ Department of Electrical and Electronics Engineering, HIT, BBSR, Odisha
}

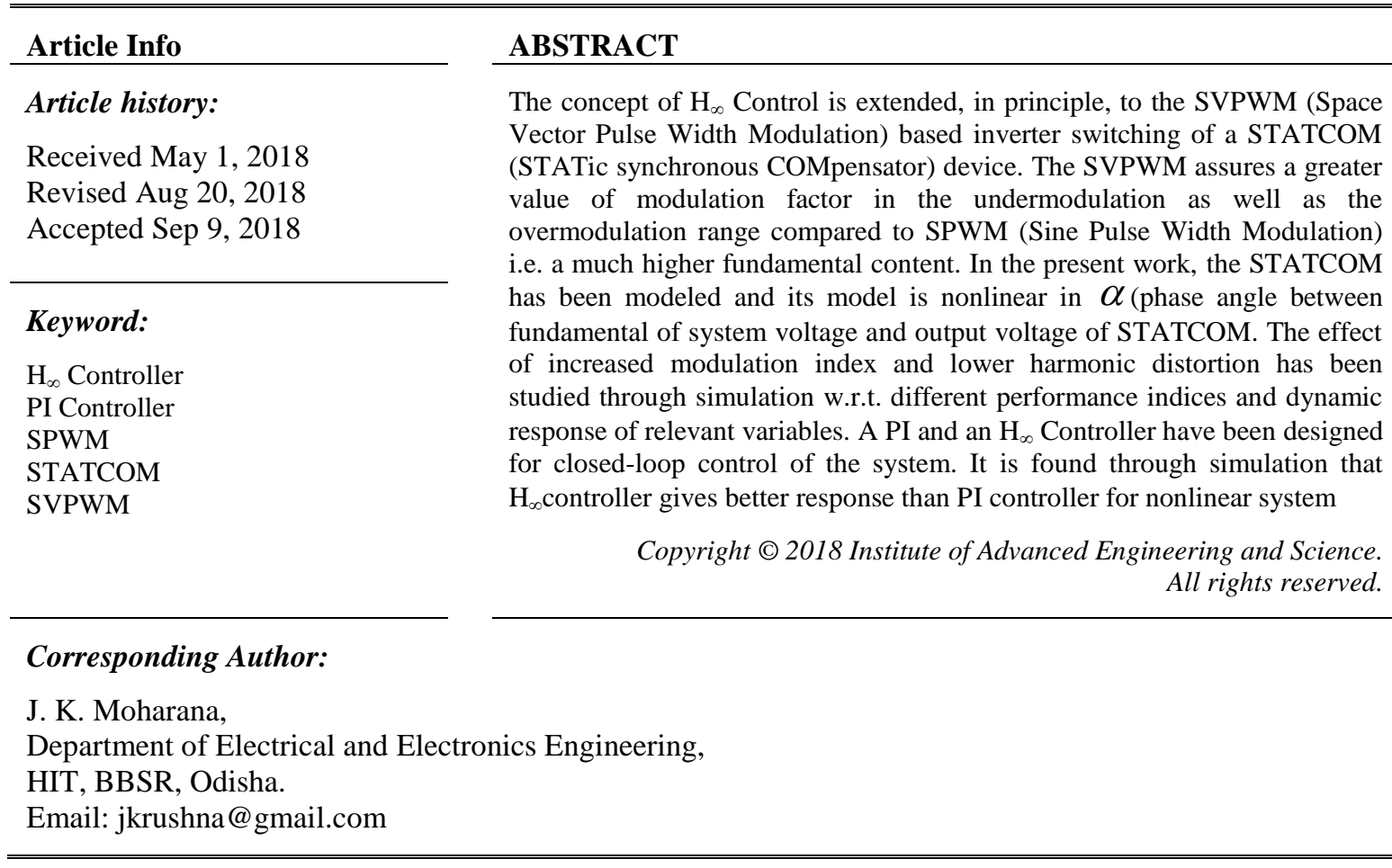

\section{INTRODUCTION}

In recent years power systems are extremely complex with long distance transmission lines and interconnected grids, which tend to become unstable as the heavy loads vary dynamically in their magnitude and power-factor. Power system stability is a key issue to determine the capacity of transmitted power, especially in a deregulated market. New transmission systems are expensive and take considerable amount of time to build up. So, in order to meet increasing power demands, utilities must rely on power export/import arrangements through existing transmission systems. Several strategies to stabilize a power system have been proposed and practically implemented so far. Reactive power (VAR) compensation has been recognized [1] as an efficient and economic means of increasing power transmission capability. Flexible A.C. Transmission Systems (FACTS) devices have of late replaced the capacitor banks, synchronous condensers and inductors, used traditionally to supply reactive power to an interconnected system. The fast response of these FACTS devices suits the needs of interconnected grid dynamics. Reactive power compensators based on voltagesourced inverter (VSI), such as STATCOM [2] are finding increasing applications at different power levels. They offer several advantages over conventional thyristorised converters [3] in terms of speed of response, flicker compensation, flexibility, and minimal interaction with the supply grid. So STATCOM's, employing a VSI with a fixed dc link capacitor, were introduced as a static replacement of synchronous condensers. In traditional synchronous condensers the field current of the synchronous motorIn [6] the dynamic response and steady state behavior of a STATCOM with SVPWM has been studied and the advantages of introducing SVPWM inverter with higher values of MI are highlighted. It is also shown that a PI Controller designed on the basis of a linearized model of the STATCOM achieves very good transient response.

The large interconnected power system is called upon to work with different values of $\alpha$, the angle between the utility voltage and the fundamental component of inverter output voltage. Also the M.I. of the inverter is to be varied over a wide range. The inherently nonlinear system also experiences plant parameter 
variation over a wide range. In this work it is shown that the PI Controller designed on the basis of the plant model, linearized about a nominal point, cannot handle the plant parameter variation over the entire range. As a remedy the plant parameter variation is included as plant uncertainty and a controller based on $\mathrm{H}_{\infty}$ optimization is used. This gives significant improvement in plant response on variation of $m$ and $\alpha$

\section{MODELLING OF THE STATCOM}

The STATCOM is, in principle, a static power electronic equivalent of a synchronous condenser with a much faster response. Its operating principles are well established [6]. Considering Figure 1, the reactive power generated or absorbed by the STATCOM, in the present case, is being controlled by only one parameter $\alpha$ (for a given value of $\mathrm{m}$, the modulation index), the phase angle between Voa, fundamental component of output voltage of inverter and Vsa, fundamental component of supply voltage. Based on the model of Figure 2, the system can be represented by the differential equation as given in (1).
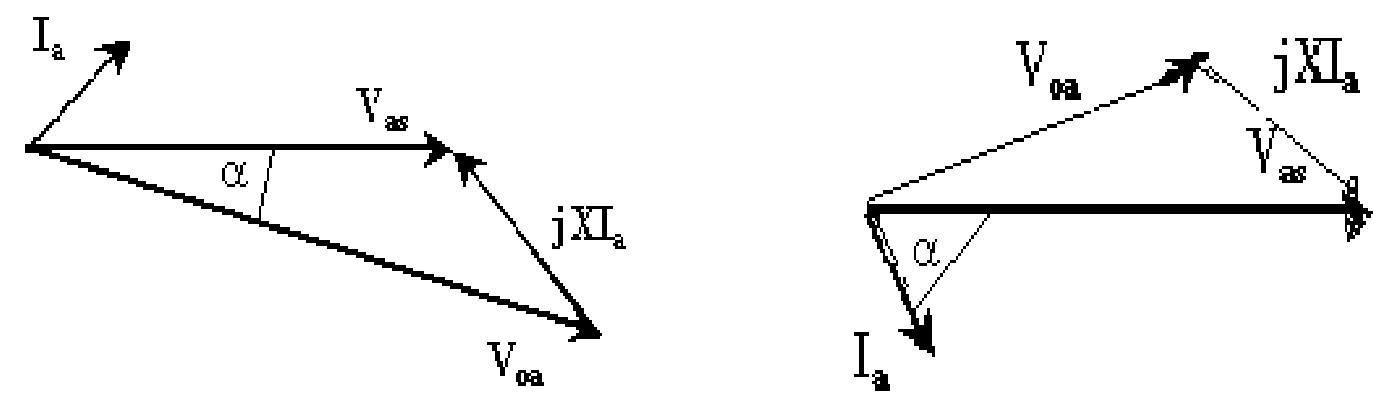

Figure 1. (a) Phasor diagram for capacitive mode, (b)Phasor diagram for inductive mode

$$
\begin{gathered}
L_{s} \frac{d i_{s a}}{d t}=-R_{s} \times i_{s a}+\left(-V_{o a}+V_{s a}\right) \\
L_{s} \frac{d i_{s b}}{d t}=-R_{s} \times i_{s b}+\left(-V_{o b}+V_{s b}\right) \\
L_{s} \frac{d i_{s c}}{d t}=-R_{s} \times i_{s c}+\left(-V_{o c}+V_{s c}\right)
\end{gathered}
$$

A power balance couples the equations across the ideal inverter. The overall state space model of the system as developed in [1] as shown in Figure2 is given in (2).

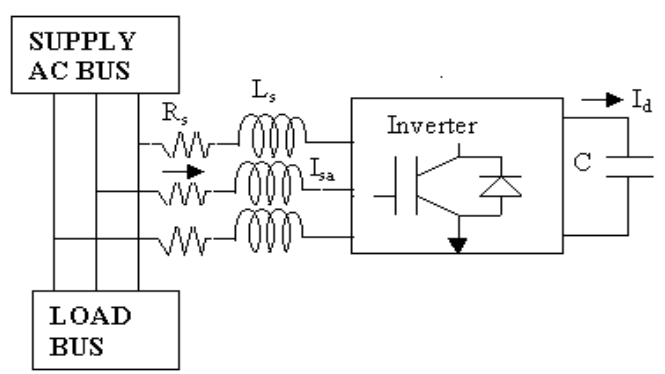

Figure 2. Schematic diagram of a STATCOM 


$$
\begin{aligned}
& \frac{d}{d t}\left[\begin{array}{c}
\dot{i}_{q} \\
\dot{i} \\
v_{d c} \\
v_{c}
\end{array}\right]=\left[\begin{array}{ccc}
-\frac{R_{S}}{L_{S}} & -\omega & 0 \\
\omega & -\frac{R_{S}}{L_{S}} & -\frac{m}{L_{S}} \\
\frac{m}{C} & 0
\end{array}\right]\left[\begin{array}{c}
i_{q} \\
i_{d} \\
v_{d c}
\end{array}\right]+\frac{V_{S}}{L_{S}}\left[\begin{array}{c}
-\operatorname{Sin} \alpha \\
\operatorname{Cos} \alpha \\
0
\end{array}\right], \\
& q_{c}=V_{S}\left[\begin{array}{lll}
-\operatorname{Cos} \alpha & \operatorname{Sin} \alpha & 0
\end{array}\right]\left[\begin{array}{c}
i_{q} \\
i_{d} \\
v_{d c}
\end{array}\right]
\end{aligned}
$$

where $\mathrm{R}_{\mathrm{s}}=$ Resistance of the coupling inductor, $\mathrm{Ls}=$ Inductance of the coupling inductor, Vs= Source Voltage, $\mathrm{C}=\mathrm{D}$.C. link capacitor, $\mathrm{m}=$ Modulation Index, $\mathrm{id}=\mathrm{d}$-axis component of the inverter current, $\mathrm{iq}=\mathrm{q}$ axis component of the inverter current, $\mathrm{vdc}=$ Voltage across the D.C. link capacitor, $\mathrm{q}_{\mathrm{c}}=$ Reactive power. The above model is found to be nonlinear in $\alpha$.

\section{TRANSIENT RESPONSE}

The system parameters are given by, $\mathrm{V}_{\mathrm{s}}=220 \mathrm{~V}, \mathrm{f}=50 \mathrm{~Hz}, \mathrm{Rs}=1 \mathrm{ohm}, \mathrm{L}_{\mathrm{s}}=5 \mathrm{mH}, \mathrm{C}=500 \mu \mathrm{F}, 0.60$ $\leq m \leq 1.14$. The steady state response of STATCOM for different values of M.I. can be easily obtained [6]. The transient responses of $i_{d}, i_{q}, v d c, p_{c} \& q_{c}$ are of interest in the present work. Figure 3 and Figure 4 show the response of $\mathrm{i}_{\mathrm{q}}$ for different values of $m$ in the capacitive and inductive modes respectively. The response becomes noticeably faster with increase in the value of $\mathrm{m}$. With higher values of $m$ the steady state is reached in half a power cycle.

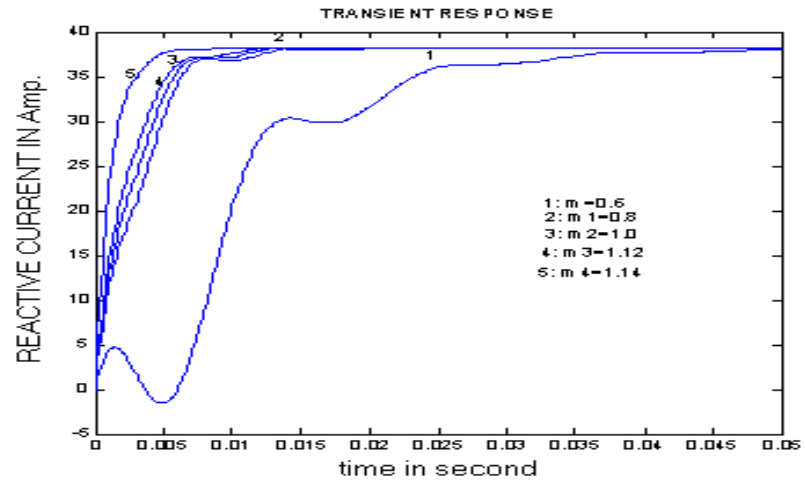

Figure 3. Transient response of $i_{q}$ in capacitive mode

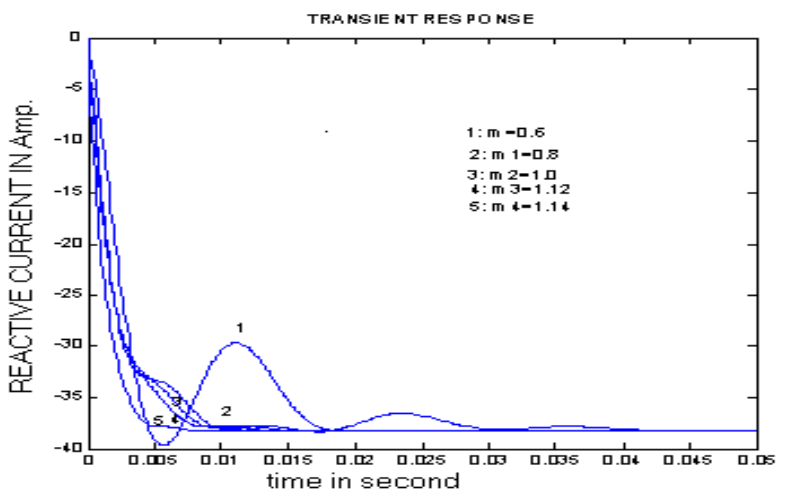

Figure 4. Transient response of $\mathrm{i}_{\mathrm{q}}$ in inductive mode 


\section{CLOSED LOOP CONTROL WITH A PI CONTROLLER}

The transient response of (2) may be improved by employing a closed loop control strategy. It may be noted that the (2a) and (2b) are nonlinear in $\alpha$. To employ the closed-loop control techniques available in literatures this system is linearized about the equilibrium point $(\alpha=0)$, which considers the perturbation to each state about the operating point. Here $\Delta \alpha$, a small perturbation to $\alpha$ is the input. The following assumptions have been taken for linearising the system:

(1) Disturbance $\Delta \alpha$.is small.

(2) The operating $\alpha$ is near zero.

The large interconnected power systems the perturbations may not be practically that small and would therefore give rise to nonlinearity. This is neglected for the present. The linearized model at any $\alpha$ is shown in (3).

$$
\begin{aligned}
& \Delta \dot{X}=\left[\begin{array}{c}
\Delta \dot{i}_{q} \\
\dot{\dot{i}_{d}} \\
\Delta \dot{v}_{d c}
\end{array}\right]=\left[\begin{array}{ccc}
-\frac{R_{S}}{L_{S}} & -\omega & 0 \\
\omega & -\frac{R_{s}}{L_{s}} & -\frac{m}{L_{s}} \\
0 & \frac{m}{C} & 0
\end{array}\right]\left[\begin{array}{c}
\Delta i_{q} \\
\Delta i_{d} \\
\Delta v_{d c}
\end{array}\right]+\left[\begin{array}{c}
-\frac{V_{s} \operatorname{Cos} \alpha}{L_{S}} \\
V_{s} \operatorname{Sin} \alpha \\
L_{S} \\
0
\end{array}\right] \Delta \alpha \\
& \Delta q_{c}=\left[\begin{array}{lll}
-V_{s} \operatorname{Cos} \alpha & V_{s} \operatorname{Sin} \alpha & 0
\end{array}\right]\left[\begin{array}{c}
\Delta i_{q} \\
\Delta i_{d} \\
\Delta v_{d c}
\end{array}\right]+\left[V_{S} \operatorname{Sin} \alpha \times i_{q}+V_{S} \operatorname{Cos} \alpha \times i_{d}\right]
\end{aligned}
$$

After putting the steady state values of $i_{q}$ and $i_{d}[6]$, the variation of output reactive power from (3) will be (4)

$$
\Delta q_{c}=\left[\begin{array}{lll}
-V_{s} \operatorname{Cos} \alpha & V_{S} \operatorname{Sin} \alpha & 0
\end{array}\right]+\left[-\frac{V_{S}^{2} \operatorname{Sin}^{2} \alpha}{R_{S}}\right]
$$

The transfer function of the above model is shown in (5)

$$
\begin{aligned}
& P(s)=\frac{\Delta q_{C}(s)}{\Delta \alpha(s)} \\
& =\frac{\frac{V_{S}^{2}}{L_{S}}\left[-s^{3} \operatorname{Sin}^{2} \alpha+s^{2}(1-3 \operatorname{Sin} \alpha)+s(A)+B\right]}{\left(s^{3}+2 s^{2} \frac{R_{S}}{L_{S}}+\left(\omega^{2}+\frac{m^{2}}{L_{S} C}+\frac{R_{S}^{2}}{L_{s}^{2}}\right) s+\frac{m^{2} R_{S}}{L_{S}{ }^{2} C}\right)}
\end{aligned}
$$

where

$$
\begin{aligned}
& A=1-3 \frac{R_{S}}{L_{S}} \operatorname{Sin}^{2} \alpha-\operatorname{Sin} \alpha(2 w \operatorname{Cos} \alpha+1)-\frac{L_{S}}{R_{S}} \operatorname{Sin}^{2} \alpha w \\
& B=\frac{\operatorname{Cos}^{2} \alpha}{L_{S} C} m^{2}-m \operatorname{Sin}^{2} \alpha\left(\frac{m}{R_{S} L_{S} C}+1\right)
\end{aligned}
$$

Over the entire operating range of the inverter, ' $m$ ' is expected to vary from $0.60 \leq m \leq 1.14$ ([1]) for higher magnitude of output voltage. Figure 5 shows the open loop response of (5) for various values of ' $m$ ' at $\alpha=0^{0}$. The closed loop control scheme for the STATCOM system is given in the block-diagram of Figure 6 . The scheme shows that ' $\alpha$ ' is the output of the PI Controller and its variation depends upon the difference between the measured reactive power with its reference. The variation of ' $m$ ' depends on the switching 
strategies of the inverter [7]. Deals with the effect of the variation of ' $m$ ' and $\alpha$ for compensating reactive power in short transient time. Hence to improve the transient response of the system, a PI Controller given by (6),

$$
K_{P I}(s)=K\left(1+\frac{1}{T_{i} s}\right)
$$

Has been designed for the transfer function in (5), taking $m=0.64$ and $\alpha=0^{0}$. Also $T_{i}=0.003, \mathrm{~K}=7.5 \times 10^{-6}$.

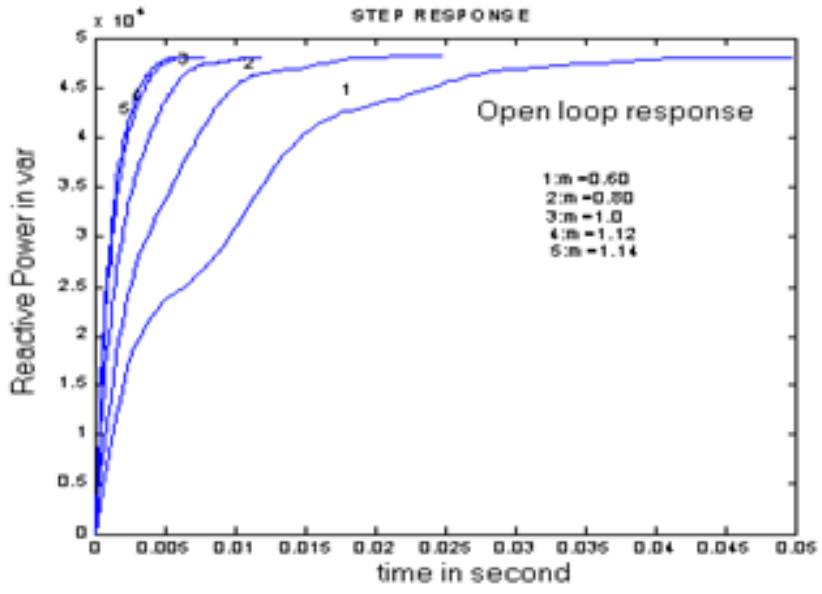

Figure 5. Open loop response

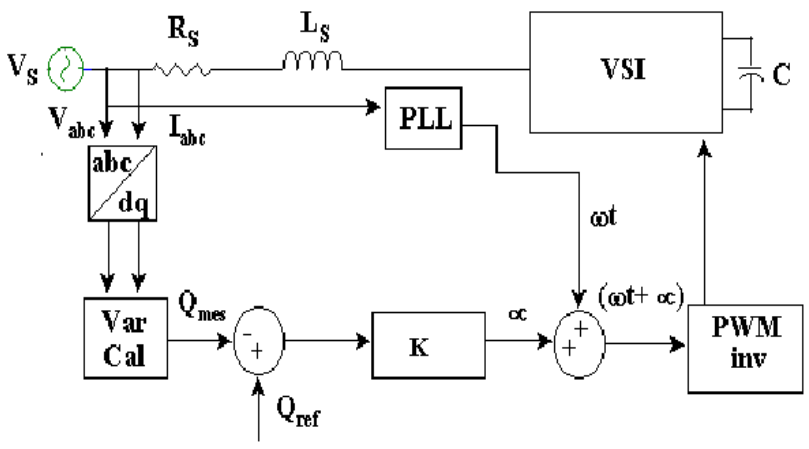

Figure 6. Proposed control block

The closed loop transient response with PI Controller is shown in Figure 7, which gives a considerablelowering in the rise time compared to the open loop response in Figure 5. Figure 8 shows the simulated reactive power response to a reference step change from 10kvar lagging to 10kvar leading with the same controller. It shows that the closed loop response tracks the input for $0.60 \leq \mathrm{m} \leq 1.12$ but it fails to track the input for $\mathrm{m}=1.14$ which is within the operating range of the system.

The PI Controller in (6) is now tested on the original nonlinear model in (2) with $\alpha=0^{0}$. Fig.10 shows the unit step response and Figure 11 the response to a step change from 10kvar lagging to 10kvar leading. It may 


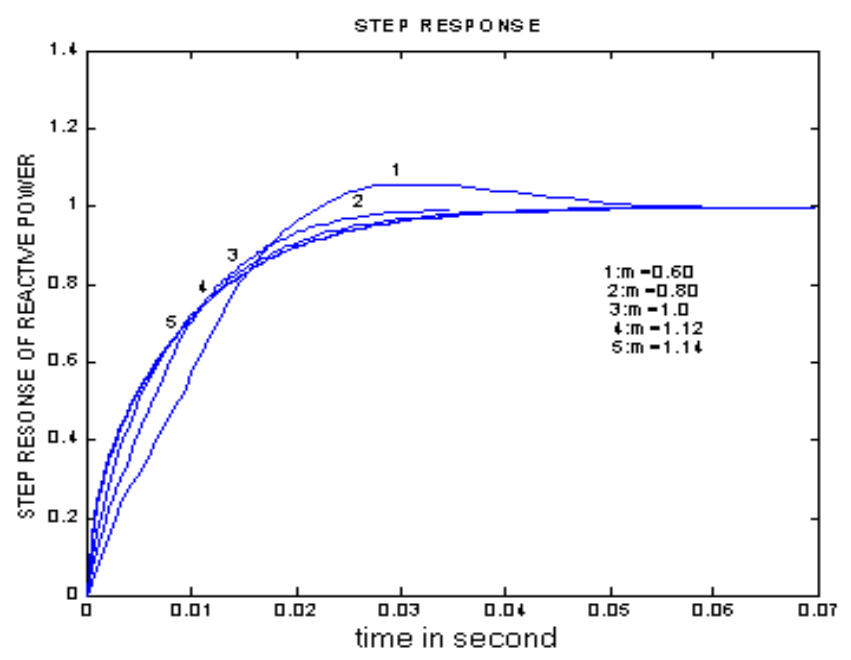

Figure 7. Step response with the PI controller

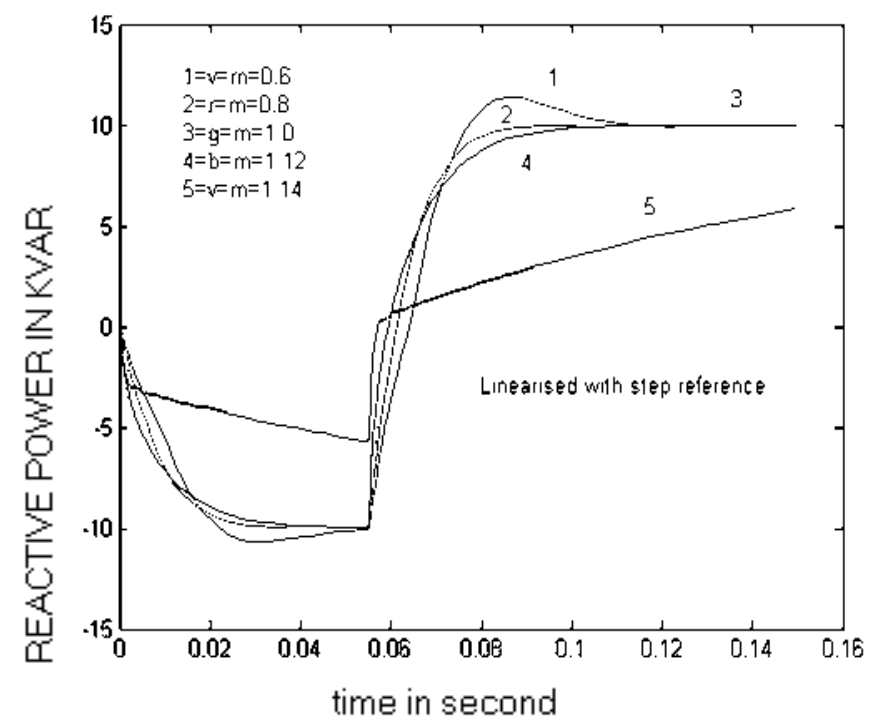

Figure 8. Simulated reactive power response

Be seen that when connected to the nonlinear system, the PI control works well only for $m=0.64$, i.e. the value considered in the linearised model in (5). The responses in both figures are seen to be unacceptable for other values of $m$. Thus it may be inferred that the PI Controller apparently cannot handle the nonlinearities associated the original plant. Hence the authors need to design an $\mathrm{H}_{\infty}$ Controller.

\section{DESIGN OF $\mathrm{H}_{\infty}$ CONTROLLER}

In this section a robust controller is designed for the nominal plant $\mathrm{P}(\mathrm{s})$ in (5) with $m=0.64$ and $\alpha=0^{0}$. The controller solves the Mixed Sensitivity problem in $\mathrm{H}_{\infty}$-optimal Control Theory [8] as explained in brief below. Step response of PI controller of original model as shown in Figure 9. In Figure 10 is simulated reactive power PI controller of original model. Let us consider the block-diagram in Figure11, where, P(s) is the 


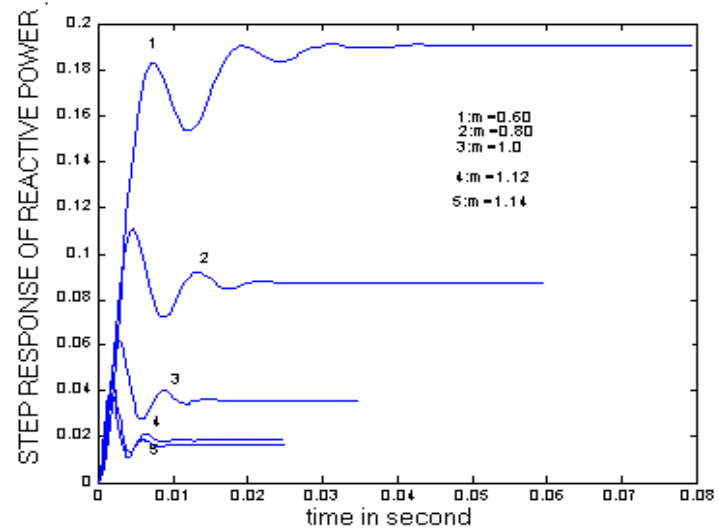

Figure 9. Step response of PI controller of original model

Nominal plant, $\mathrm{K}(\mathrm{s})$ is the $\mathrm{H}_{\infty}$ controller, $\mathrm{W}_{1}(\mathrm{~s})$ is the sensitivity weighting function and $\mathrm{W}_{2}(\mathrm{~s})$ is the complementary sensitivity weighting function, $\mathrm{y}(\mathrm{t})$ is the measured output, $\mathrm{u}(\mathrm{t})$ the controlled input, $\mathrm{w}(\mathrm{t})$ the.

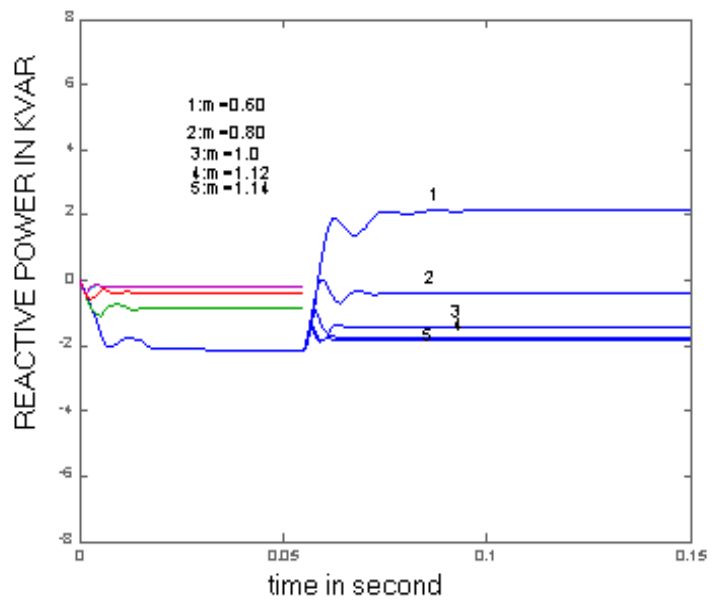

Figure 10. Simulated reactive power PI controller of original model

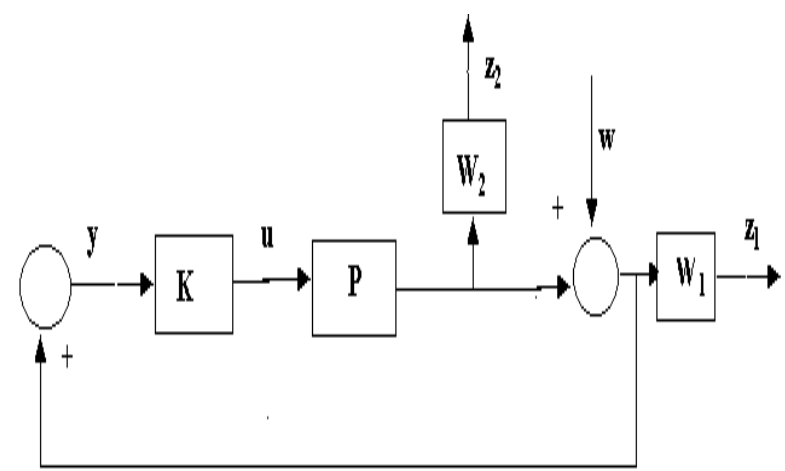

Figure 11. Mixed Sensitivity Problem 
exogenous input which may include the disturbance. The controlled output $\mathrm{z}(\mathrm{t})$ is given by

$$
z=\left[\begin{array}{l}
z_{1} \\
z_{2}
\end{array}\right]
$$

and the closed loop transfer function from $\mathrm{w}$ to $\mathrm{z}$ can be denoted by $\mathrm{T}_{\mathrm{zw}}$. The augmented plant is given,

$$
G=\left[\begin{array}{cc}
W_{1} & W_{1} P \\
0 & W_{2} P \\
I & P
\end{array}\right]
$$

which relates

$$
\left[\begin{array}{l}
z_{1} \\
z_{2} \\
y
\end{array}\right]=G\left[\begin{array}{l}
w \\
u
\end{array}\right]
$$

Then the control problem is to find a controller $\mathrm{K}(\mathrm{s})$ such that

1. the closed-loop system is internally stable, and,

2. the $\infty$-norm of the closed loop transfer function $\mathrm{T}_{\mathrm{zw}}$ satisfies,

$$
\|\mathrm{TzW}\| \infty<\gamma
$$

The weighting function for sensitivity $\mathrm{S}(\mathrm{s})$ has been determined for $5 \%$ overshoot, $\xi=0.69$, $\mathrm{w}_{\mathrm{b}}=409.85$, steady state error $=0.1(7)[8]$.

$$
W_{1}(s)=\frac{(0.2 s+409.85)}{(s+40.98)}
$$

The weighting function for complementary sensitivity $\mathrm{T}(\mathrm{s}), \mathrm{W}_{2}(\mathrm{~s})$, is chosen assuming multiplicative perturbation such that (8)

$$
\frac{|\tilde{P}(s)-P(s)|}{|P(s)|} \leq\left|W_{2}(s)\right|
$$

where, the nominal plant is $\mathrm{P}(\mathrm{s})$ as in (5) with $m=0.64$ and $\alpha=0^{0}$ and the perturbed plant is $\widetilde{P}(s)$ which is given by (5) with $m=1.14$ and $\alpha=5^{0}$. Hence (9),

$$
W_{2}(s)=\frac{\widetilde{P}(s)-P(s)}{P(s)}
$$

The zero in $\mathrm{W}_{1}(\mathrm{~s})$ in (7) being far away may be neglected and finally we get (10),

$$
W_{1}(s)=\frac{10}{(s+0.4)}
$$

After computing $\mathrm{W}_{2}$ (s) from (9) we adjust it to one which obeys (8) as well as: 


$$
\left|W_{1}^{-1}(s)\right|+\left|W_{2}^{-1}(s)\right| \geq 1 \text {, for all frequencies. }
$$

The final value is (11),

$$
W_{2}(s)=\frac{s}{\left(s+10^{2}\right)}
$$

The Bode plots of $W_{1}^{-1}(s)$ and $W_{2}^{-1}(s)$ are shown in Figure. 12 The weighting functions in (10) and (11) together with the nominal plant $\mathrm{P}(\mathrm{s})$ are used in the Robust Control Toolboxin MATLAB to yield the $\mathrm{H}_{\infty}$ Controller $\mathrm{K}_{\mathrm{H}}$. The step response of the nominal plant in closed loop with the $\mathrm{H}_{\infty}$ controller, on variation of $\alpha$ with constant $\mathrm{m}$ and on variation of $m$ with constant $\alpha$ and also on variation of $\mathrm{m}$ and $\alpha$ are shown in Figure 13, 14 and 15 respectively, which give faster response with no steady state error. So reactive power can be compensated for this nonlinear system by $\mathrm{H}_{\infty}$ controller. Figure 16, 17, and 18 show the response to a step change from 10kvar lagging to 10kvar leading on variation of $\alpha$ with constant $\mathrm{m}$ and variation of $\mathrm{m}$ with constant of $\alpha$ and also on variation of both $m$ and $\alpha$ respectively. Hence all the responses are accepted. Also it may be seen that when connected to the nonlinear system, the PI control does not work well but $\mathrm{H}_{\infty}$ Controller apparently works well.

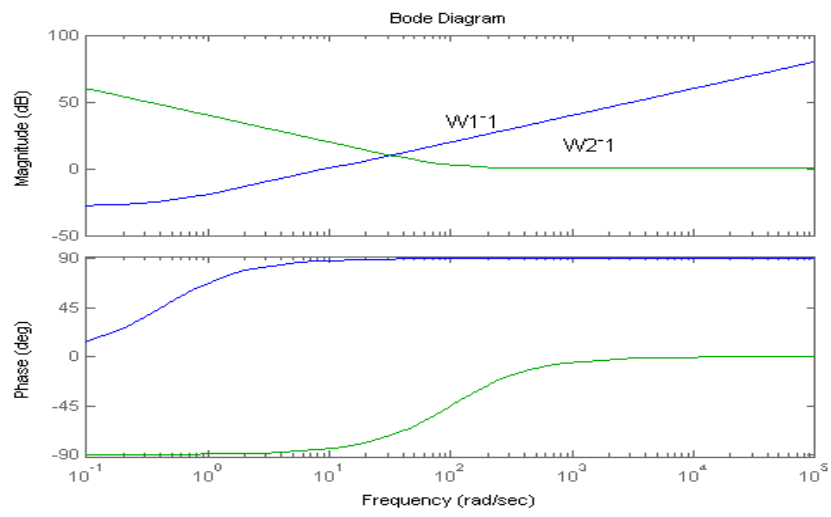

Figure 12. Bode plots of $W_{1}^{-1}(s)$ and $W_{2}^{-1}(s)$

$$
K_{H}=\frac{86 \times 10^{5}\left(s^{2}+220 s+1.3 \times 10^{4}\right)\left(s^{2}+227 s+2.6 \times 10^{5}\right)}{\left(s+9 \times 10^{12}\right)(s+84)(s+.41)\left(s^{2}+200 s+1.6 \times 10^{5}\right)}
$$

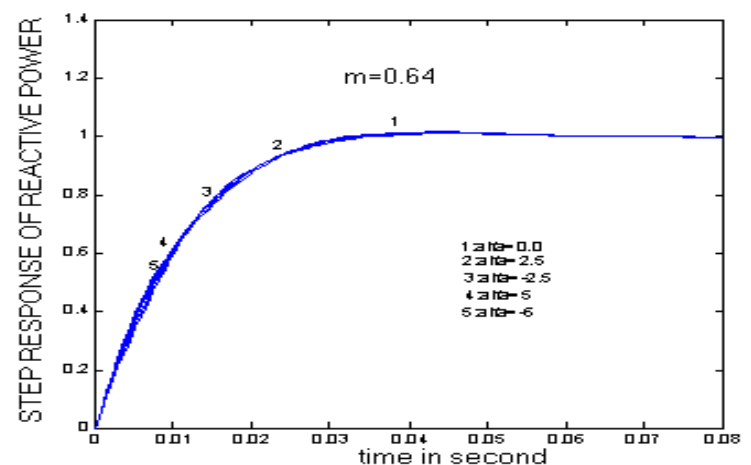

Figure 13. Step response of the linearized model with $\mathrm{H}_{\infty}$ controller with varying $\alpha(m=0.64)$. 


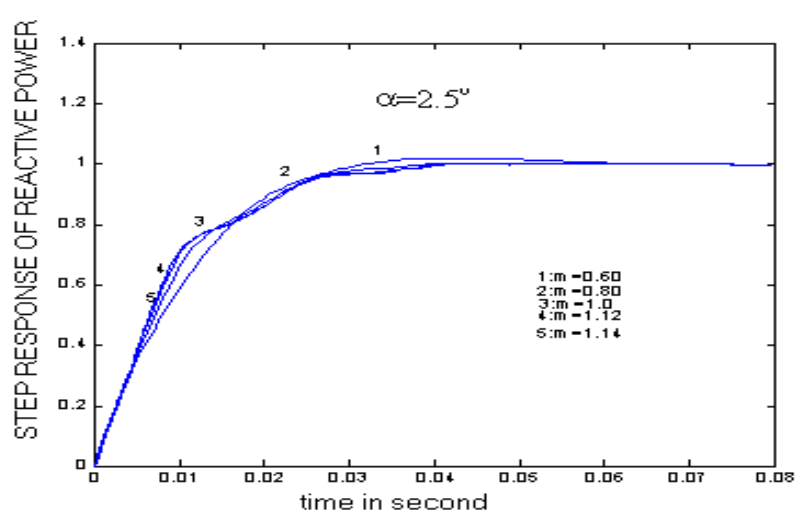

Figure 14. Step response of the linearized model with $\mathrm{H}_{\infty}$ controller with varying of $m\left(\alpha=2.5^{0}\right)$.

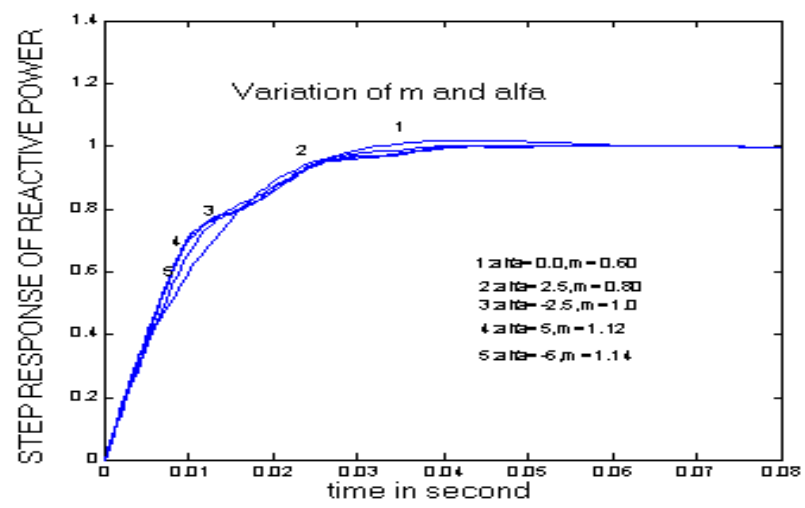

Figure 15. Step response of the linearized model with $\mathrm{H}_{\infty}$ controller on variation of $m$ and $\alpha$.

\section{COMPARISON OF THE PI AND $\mathrm{H}_{\infty}$ CONTROLLERS}

The tracking and disturbance rejection properties of the PI Controller are compared withthat of the $\mathrm{H}_{\infty}$ Controller. It is seen that in case of the $\mathrm{H}_{\infty}$ Controller, the speed of response as well as the steady state error may be improved by adjusting the gain of $W_{1}(s)$ and $W_{2}(s)$ for varying $m$ from 0.60 to 1.14 and $\alpha$ from 0 to $\pm 2.5^{\circ}$. Both the linearised and original nonlinear systems are seen to operate quite fast on variation of $m$ and $\alpha$. It seems that the $\mathrm{H}_{\infty}$ Controller handles nonlinearity in better way, which is the main objective of the paper. PI Controller is only suitable for linearised model on variation of $m$ from 0.60 to 1.12.

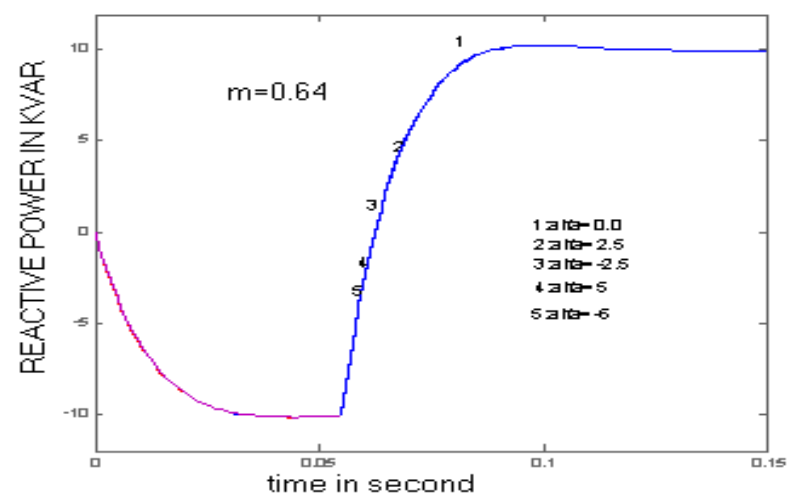

Figure 16. Simulated reactive power response with $\mathrm{H}_{\infty}$ Controller on variation of $\alpha$ and constant of $\mathrm{m}=0.64$. 


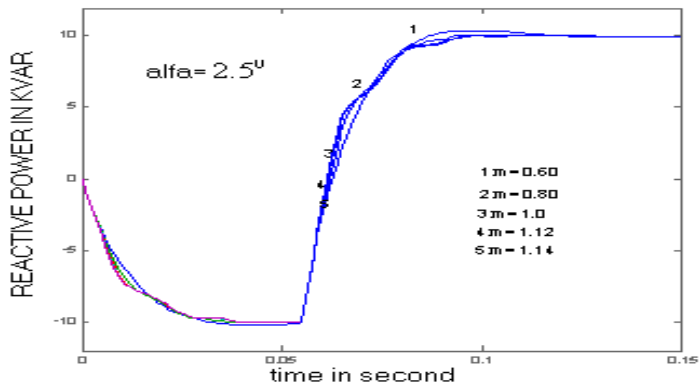

Figure 17. Simulated reactive power response with $\mathrm{H}_{\infty}$ Controller on variation of $\mathrm{m}$ and constant of $\alpha$

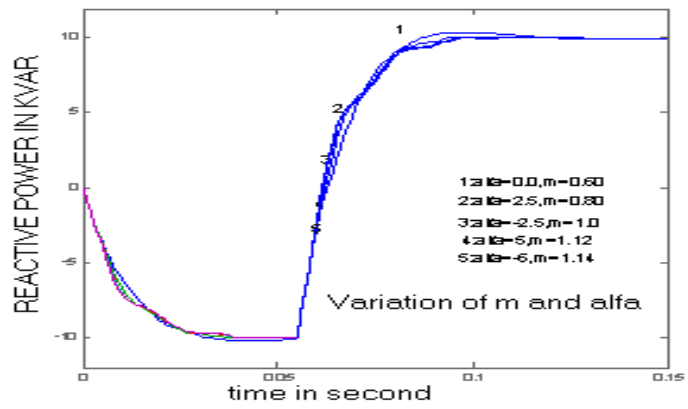

Figure 18. Simulated reactive power response with $\mathrm{H}_{\infty}$ Controller on variation of $\mathrm{m}$ and $\alpha$

\section{CONCLUSION}

A PI Controller is designed to improve the transient response of nominal model. $\mathrm{H}_{\infty}$ Controller has been designed to improve the transient response of the nominal and original model along with variation of modulation indices and phase angle. A novel scheme of employing $\mathrm{H}_{\infty}$ controller with SVPWM switching of the converter is proposed and simulated

\section{ACKNOWLEDGMENT}

The authors would like to acknowledge the support received from the All India Council of Technical Education as this work is an outcome of an AICTE-RPS Project. The authors are also thankful to the ViceChancellor and Head, Dept. of Electrical Engineering, BengalEngineering \& ScienceUniversity, Shibpur for all the support received.

\section{REFERENCES}

[1] H.M.Rasid, "Power Electronics Handbook" Academic Press, 2001.

[2] A.T.Johns, A.Ter-Gazarian, and D.F.Wame, ”Flexible AC Transmission Systems (FACTS) ” IEE Power and Energy Series, London, U.K.

[3] R.M.Mathus and R.K.Varma, “Thyristors_based FACTS Controllers for Electrical Transmission Systems,” IEEE Press, Wiley-Interscince Publication.

[4] C.Shauder and H.Mehta, "Vector Analysis and Control of Advanced Static VAR Compensators",IEE Proc,140,No.4,July,1993.

[5] L.T.Moran, P.D.Ziogas, and G.Joos, "Analysis and Design of a Three Phase Synchronous Solid State VAR Compensator" IEEE Trans.Industrial Application, Vol.25, No.4, pp.598-608.

[6] M.Sengupta, J.K.Moharana, and A.Sengupta, "Study on an Advanced Static VAR Compensator switched from a Space Vector PWM inverter -Analysis, Simulation and Comparisons with the conventional Sinusoidal PWM case", NPEC 2003,IIT Mumbai, Oct 16-17,pp.72-78.

[7] B.K.Bose, "Modern Power Electronics And AC Drives" LPE Pearson Education Asia

[8] K.Zhou and J.C.Doyle, "Essentials of Robust Control” Prentice Hall, 1997.

Analytically modeling, design and analysis a nonlinear controller for a statcom operations (J.K.Moharana) 